\title{
Combined plasma rich in growth factors and adipose-derived mesenchymal stem cells promotes the cutaneous wound healing in rabbits
}

\author{
Deborah Chicharro', Jose M. Carrillo', Mónica Rubio', Ramón Cugat², Belén Cuervo', Silvia Guil³, \\ Jerónimo Forteza ${ }^{4}$, Victoria Moreno ${ }^{5}$, Jose M. Vilar ${ }^{6^{*}}$ (iD and Joaquín Sopena ${ }^{1}$
}

\begin{abstract}
Background: The use of Plasma Rich in Growth Factors (PRGF) and Adipose Derived Mesenchymal Stem Cells (ASCs) are today extensively studied in the field of regenerative medicine. In recent years, human and veterinary medicine prefer to avoid using traumatic techniques and choose low or non-invasive procedures. The objective of this study was to evaluate the efficacy of PRGF, ASCs and the combination of both in wound healing of full-thickness skin defects in rabbits. With this purpose, a total of 144 rabbits were used for this study. The animals were divided in three study groups of 48 rabbits each depending on the administered treatment: PRGF, ASCs, and PGRF+ASCs. Two wounds of $8 \mathrm{~mm}$ of diameter and separated from each other by $20 \mathrm{~mm}$ were created on the back of each rabbit: the first was treated with saline solution, and the second with the treatment assigned for each group. Macroscopic and microscopic evolution of wounds was assessed at 1, 2, 3, 5, 7 and 10 days post-surgery. With this aim, 8 animals from each treatment group and at each study time were euthanized to collect wounds for histopathological study.
\end{abstract}

Results: Wounds treated with PRGF, ASCs and PRGF+ASCs showed significant higher wound healing and epithelialization rates, more natural aesthetic appearance, significant lower inflammatory response, significant higher collagen deposition and angiogenesis compared with control wounds. The combined treatment PRGF +ASCs showed a significant faster cutaneous wound healing process.

Conclusions: The combined treatment PRGF+ASCs showed the best results, suggesting this is the best choice to enhance wound healing and improve aesthetic results in acute wounds.

Keywords: Adipose-derived mesenchymal stem cells (ASCs), Plasma rich in growth factors (PRGF), Wound healing, Rabbits, Skin, Regenerative medicine, Growth factors

\section{Background}

Wound healing is a complex and dynamic process that includes inflammation, tissue formation and remodeling, involving the interaction of multiple cell types, cytokines, growth factors, and chemokines [1, 2]. When the physiological mechanisms of wound healing are interrupted, chronic or non-healing wounds can appear [3]. A structured assessment of the wound healing should

\footnotetext{
*Correspondence: jose.vilar@ulpgc.es

${ }^{6}$ Animal Pathology Department, IUIBS, Universidad de Las Palmas de Gran

Canaria, 35416, Transmontaña s/n, Arucas, Las Palmas, Spain

Full list of author information is available at the end of the article
}

include basic components of the healing process such as inflammatory response evaluation, angiogenesis, fibroplasia and epithelialization [4]. The importance of evaluating macroscopic scar quality has also been highlighted by other authors [5].

Regenerative skin wound therapy is a novel and rapidly developing field of biomedical research that aims to promote wound healing [6] and focuses on replacing, restoring and regenerating damaged cells, tissues and organs [7].

Stem cells, with their properties to self-renew and undergo differentiation are being extensively assessed for their wound healing potential [8]. Adipose-derived stem

(c) The Author(s). 2018 Open Access This article is distributed under the terms of the Creative Commons Attribution 4.0 International License (http://creativecommons.org/licenses/by/4.0/), which permits unrestricted use, distribution, and reproduction in any medium, provided you give appropriate credit to the original author(s) and the source, provide a link to the Creative Commons license, and indicate if changes were made. The Creative Commons Public Domain Dedication waiver (http://creativecommons.org/publicdomain/zero/1.0/) applies to the data made available in this article, unless otherwise stated. 
cells (ASCs) are an appealing source of mesenchymal stem cells (MSCs) due to their abundant availability, good expansion capacity, their ability to proliferate in culture, and cryopreservation capacity [9]. They have been already successfully used in the treatment of soft tissue defects, scars, and burn injuries by showing an acceleration and improvement on the quality of the wound healing process [10].

ASCs promote angiogenesis, epithelial migration, secretion of growth factors and differentiate into multiple lineages [11]; thus, enhance the wound healing process with less scar formation. The exact mechanism of action is still under investigation. It is postulated that ASCs can stimulate tissue regeneration by differentiating into epithelial cells or by secreting paracrine factors to activate endogenous repair mechanisms [12].

Blood platelets are a natural source of growth factors and cytokines that help accelerating the normal wound healing process [13]. The main growth factors which are responsible for promoting the re-epithelialization process are EGF, FGF-2, IGF-1 and TGF $\alpha$ [14]. These growth factors trigger biological effects such as cell migration, angiogenesis, cell proliferation and differentiation, promote extracellular production and inflammation resolution. These are key elements in the tissue repair process [15]. Plasma Rich in Growth Factors (PRGF) is a portion of autologous plasma enriched of proteins and circulating growth factors with a platelet concentration above baseline [16]. The advantages and merits of PRGF are apparent since it is a simple, cost-effective and safe product [9]. Successful clinical applications have been reported using these Platelet Rich Plasma (PRP) derivates in wound and soft tissue repair [17], cosmetic surgery [18], nervous tissue repair [19], orthopaedics [20] and chronic ulcers [21].

A synergetic effect is suggested when ASCs and PRGF are used together, where growth factors act as vehicles and potentiators of MSCs [22, 23].

Based on this, the aim of the study is to compare the efficacy of using PRGF, ASCs and the combination of both and assess a possible synergistic effect in acute full-thickness cutaneous wounds in a rabbit model.

\section{Methods}

\section{Animals}

A total of 144 adult female New Zeland rabbits (8 months old), 48 animals per treatment group (PRGF, ASCs or PRGF+ASCs) and therefore 8 animals per study time (1, $2,3,5,7$ and 10 days) with an average weight of $3152 \mathrm{~g}$ were used to carry out a prospective randomized experimental study. Animals were housed in spacious individual cages with food and water ad-libitum and were monitored daily for signs of discomfort, infection and weight loss. An acclimatization period of 7 days was established before starting the experiment to allow animal adaptation.
Complete physical examination, haematology and serum biochemical analyses were also performed and results were within normal reference range values.

This study was approved by the Ethics Committee of Animal Welfare (CEBA) of the university CEU Cardenal Herrera of Valencia (Spain) in accordance with European legislation (86/609/CEE) .

\section{Plasma rich in growth factors (PRGF) preparation}

$\mathrm{PRGF}^{\circ}$-Endoret ${ }^{\circ}$ technology was used to obtain an autologous preparation of PRP. A total of $5 \mathrm{ml}$ of blood was collected from the auricular artery of each rabbit under sedation with intramuscular dexmedetomidine $(10 \mu \mathrm{g} / \mathrm{kg})$, ketamine $(20 \mathrm{mg} / \mathrm{kg})$ and morphine $(0.2 \mathrm{mg} /$ $\mathrm{kg}$ ) and under sterile conditions in vacutainer sodium citrate 3.8\% tubes (Blood collecting tubes ${ }^{\bullet}$, BTI Biotechnology institute, Álava, Spain). The tubes were centrifuged at $460 \mathrm{~g}$ for eight minutes (PRGF ${ }^{\circ}$ System III, Biotechnology Institute, Álava, Spain) to separate the different blood phases. Two sterile fractionation tubes were used to collect PRGF and the Plasma Poor in Growth Factors (PPGF), with sterile pipettes of $200 \mu \mathrm{l}$ and $1000 \mu \mathrm{l}$ respectively. The $0.5 \mathrm{ml}$ fraction located immediately above the buffy coat corresponded to PRGF. Just before cutaneous infiltration to activate platelets for growth factors release, $10 \%$ calcium chloride was added to PRGF $(50 \mu \mathrm{l} / \mathrm{ml}$ of PRGF) (Fig. 1a, b, c).

\section{Adipose-derived mesenchymal stem cell (ASCs) isolation, culture and differentiation}

Allogenic ASCs were used from an individual donor rabbit coming from the same institution. Under general anesthesia and sterile conditions, a total of $31.3 \mathrm{~g}$ of inguinal adipose tissue was collected. Additionally, a $20 \mathrm{ml}$ blood sample was obtained from the external jugular vein into blood collection tubes without anticoagulant (BD Vacutainer ${ }^{\bullet}$, Plymouth, UK). Both samples were transported to the Research Center Príncipe Felipe (CIPF) in an enclosed package at $4{ }^{\circ} \mathrm{C}$ where ASCs isolation and cell culture was carried out.

At laboratory, adipose tissue was washed with Phosphate Buffered Saline Solution (PBS) plus antibiotics. Total collected fat was distributed into ten grams of adipose tissue for enzymatic reaction, by incubating in a PBS solution containing penincilin, streptomycin (Gibco $15,140)$ and collagenase (0.07\% Sigma C9891 CA, USA). The tissue was then manually cut into small pieces and digested overnight at $37{ }^{\circ} \mathrm{C}$. The following day, the digested adipose tissue was washed and the resulted stromal vascular fraction was cultured in autologous serum allowing cells to grow until one million cells per gram were obtained and subjected up to three consecutive passages before cell transplantation. For tissue 

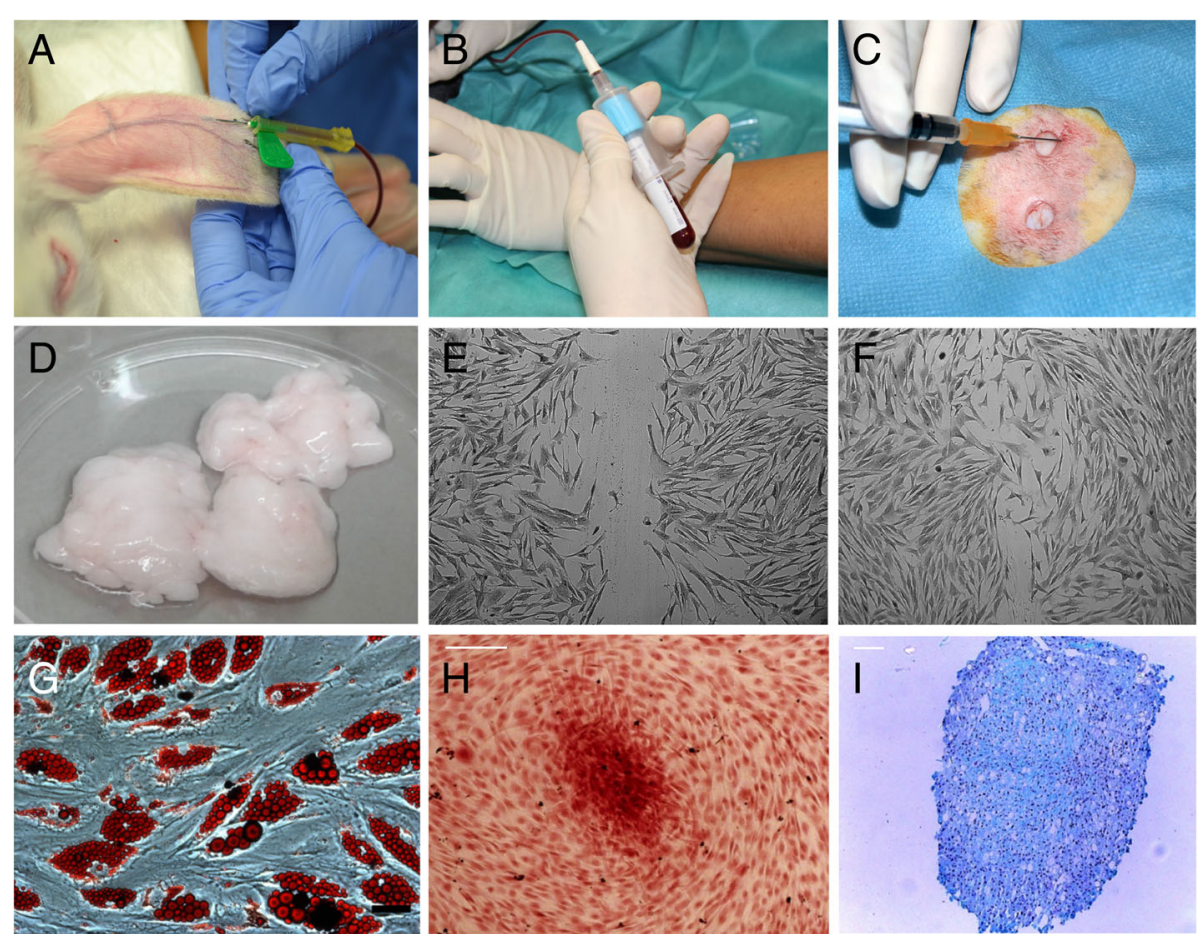

Fig. 1 Preparation and infiltration of Plasma Rich in Growth Factors (PRGF) together with Adipose-Deived Mesenchymal Stem Cells (ASCs) isolation, culture and differentiation. a Blood extraction from auricular artery of each rabbit ( $5 \mathrm{ml}$ ). b Blood collection in vacutainer sodium citrate 3,8\% tubes (BTI Biotechnology institute, Álava, Spain). c Perilesional PRGF infiltration into corresponding cutaneous wounds. $\mathbf{d}$ Harvested adipose tissue from donor rabbit. e, $\mathbf{f}$ Morphology of ASCs cultured in vitro, migration and wound closure capacity in vitro. $\mathbf{g}$, $\mathbf{h}$, i Multipotent ability of ASCs by induced differentiation of adipocytes $(G)$ is shown by Oil Red staining, scale bar: $15 \mu \mathrm{m}$ osteoblasts (H) showing calcium accumulation by Alizarin Red staining, scale bar: $100 \mu \mathrm{m}$; and chondrocytes (I) showing high content of condroitinsulfate enriched matrix stained by Alcian Blue, scale bar: $100 \mu \mathrm{m}$

transplantation, one million cells were suspended in growth medium using $10 \%$ rabbit serum.

For induced differentiation, ASCs after passage 4 were subjected, to induce adipogenesis, osteogenesis and chondrogenesis. Briefly, adipogenesis was induced in confluent ASC culture for 12 days in the presence of differentiation medium (Adipose Derived stem cell Basal Medium; Lonza Co). The adipogenic differentiation was evaluated by Oil Red staining of the lipid vacuoles in formalin fixed cultures; For osteogenesis, ASC were seeded in coated plates in medium containing $0.1 \mu \mathrm{M}$ dexamethasone, $50 \mu \mathrm{M}$ Asc2P and $10 \mathrm{mM} \mu$-glycerophosphate (Osteogenic Basal Medium; Lonza Co.) with 10\% FBS for 4 weeks. For detection of extracellular calcium deposits Alizarin Red staining was used in formalin fixed cultures; Alizarin Red Solution ( $0.2 \mathrm{~g} / \mathrm{L}$ water) was incubated for $2-3 \mathrm{~min}$, until the reaction was observed microscopically. Chondrogenesis was induced from ASC in "Micromass" in the presence of TGF- $\beta 1$ and $3(10 \mathrm{ng} / \mathrm{ml})$, Asc $2 \mathrm{P}(50 \mu \mathrm{M})$ and insulin $(6.25 \mu \mathrm{g} / \mathrm{ml})$ (Chondro BulletKit; Lonza Co.) for 4 weeks. Alcian blue $(0.1 \mathrm{~g} / \mathrm{L}$ in water, $\mathrm{pH} 1.0)$ was used to detect the presence of enrichment of sulphated proteoglycans in the extracellular matrix. (Fig. 1d, e, f, g, h, i).

\section{Wound model and treatments}

Rabbits were premedicated with dexmedetomidine (10 $\mu \mathrm{g} / \mathrm{kg} ; \quad$ Dexdomitor ${ }^{\circ}$, Esteve, Spain), ketamine (20 $\mathrm{mg} / \mathrm{kg}$; Imalgene, Merial, Spain) and morphine (0.2 mg $/ \mathrm{kg}$; B-Braun, Germany). The dorsal thoracolumbar area of rabbits was clipped and prepared for aseptic surgery. General anesthesia was mask induced and mantained with sevoflurane (Sevoflo ${ }^{\circ}$, Esteve, Spain).

Two full-thickness wounds of $8 \mathrm{~mm}$ in diameter and separated $20 \mathrm{~mm}$ from each other were created on the dorsal thoracolumbar area of each rabbit using disposable dermal biopsy punches (Kruuse, UK); one for the placebo treatment (saline solution), and the other for the study treatment (PRGF, ASCs, or PGRF+ASCs). Each wound was treated injecting perilesionally with $0.1 \mathrm{ml}$ of the corresponding treatments; ASCs preparations contained at least $1 \times 10^{6}$ cells. Cefovecin as prophylactic antibiotic and buprenorphine during 3 days was administered. Rabbits were then randomly divided into six groups according to their survival time $(1,2,3,5,7$, and 10 days after wounding), subsequently a total of 8 animals from each treatment group and at each study time $(1,2,3,5,7$, and 10 days after wounding) were 
euthanised and wounds were evaluated macroscopically and histologically. Study times were chose based on a preliminary study in rabbits not published yet were a significant acceleration of the wound healing process was found at day 7 but not at day 14. In the same way, other authors also observed significant differences during the early healing period $[13,24]$.

\section{Macroscopic study}

Rabbits were euthanized following spanish royal decree $53 / 2013$ with an overdose of intracardiac pentobarbital. Immediately after sacrifice, a macroscopic assessment of each wound at the different study times was made by two blinded investigators. Thus, good quality photographs were taken for subsequent digital study.

Wound closure was calculated by measuring the largest (original size) and smallest (open wound area) diameters of the wounds as a wound healing percentage ((largest diameter-smallest diameter/largest diameter)*100). Additionally, based on Oppenheimer et al. [5] semi-quantitative scale, scar quality was evaluated based on color (1:hiperpigmentated, 2:pigmented, 3:red, 4:almost-normal, 5:normal), thickness (1:keloid, 2:hyperthrophic, 3:almost-normal, 4:normal), and wound retraction (1:very retracted, 2:mild retraction, 3:no retraction). Infection was categorized as a yes or no condition based on the presence or abscense of abcess or discharge of some kind of exudates such as seropurulent, haemopurulent or pus.

\section{Tissue processing, sectioning and staining}

For histopathological study, tissues from every study time were fixed in $4 \%$ formalin for $24 \mathrm{~h}$, prior to processing for paraffin embedding. Sections of $5 \mu \mathrm{m}$ containing the entire wound area were obtained and stained with H\&E for analysis of re-epithelialization and inflammatory infiltrate intensity and Masson's trichome staining was used to assess the degree of collagen deposition and angiogenesis.

The stained sections were digitalized with the use of a photomicroscope and an attached digital camera, and the histological images were transferred to a computer equipped with image analysis software (Image Pro-Plus ${ }^{\circ}$, Media Cybernetics, USA) to perform quantitative measurements by two blinded pathologists.

\section{Microscopic study}

In $H \& E$ stained sections, a representative histological image including the entire wound and surrounding healthy tissue was captured using Pannoramic Viewer software (3DHISTECH) to calculate the epithelialization rate percentage. The epithelial gap (distance between the advancing edges of epithelium) and the original histological wound distance (thicker epithelium) was measured with the freehand tool to calculate the percentage of re-epithelialization ((original distance-epithelial gap/ original distance)*100). Moreover, inflammatory infiltrate intensity and distribution was also evaluated with $\mathrm{H} \& \mathrm{E}$ stained sections. Entire dermis was evaluated based on a semi-quantitative scale published by Lowry et al. [25] for intensity inflammatory infiltrate assessment (0:no infiltration, 1:mild infiltration, 2:strong infiltration, 3:severe infiltration) and distribution (1:focused beneath epidermis, 2:diffuse beneath epidermis, 3:Both).

In Masson trichrome stained sections, six histological images per slide were captured (three superficial and three deep dermis). Angiogenesis was quantified by direct counting of blood vessels based in the average of the six histological captures. To asses the percentage of collagen deposition, mature collagen (dark blue) was determined via quantitative morphometry using Image Pro Plus software, by transforming the dark blue color to black and white pictures, where the white area corresponded to the mature collagen, which was expressed as the percentage of pixels of positive colllagen staining divided by total pixels of the image.

\section{Statistical analysis}

A descriptive study of the mean, standard deviation and confidence intervals was made for each variable. A value of $p<0.005$ was considered significant. Nonparametric Kruskal-Wallis tests were used to compare non-normally distributed variables and an ANOVA test for variables which followed a normal distribution. Normality of data was tested in every quantitative variable with Shapiro-Wilk test and variance homogeneity with Levene test.

The data were processed using the SPSS 20.0 programm for Mac (SPSS Inc., Chicago, USA).

\section{Results}

\section{Wound closure and epithelialization rate evaluation}

Wounds treated with PRGF, ASCs or combination of both showed significant faster wound healing rates compared to control wounds throughout the study except at day $10(p<0.001)$. When single therapies were compared, ASCs demostrated at day 7 to accelerate the wound healing process more efficiently than PRGF $(p<$ 0,001) (Fig. 2). Additionally, the ASCs+PRGF group demonstrated significant faster wound closure at days 2, 5 and 7 compared with PRGF $(p<0.001)$.

Histological analysis of wounds showed as, in the same manner, ASCs+PRGF treated wounds presented faster epithelialization rates at days 2,3 and $5(p<0.001)$ compared to PRGF, ASCs and control wounds (Fig. 3).

\section{Aesthetic assessment of wounds}

No statistical significant differences were observed regarding scar retraction and infection variables. However, scar color and thickness tended to be almost or completely 

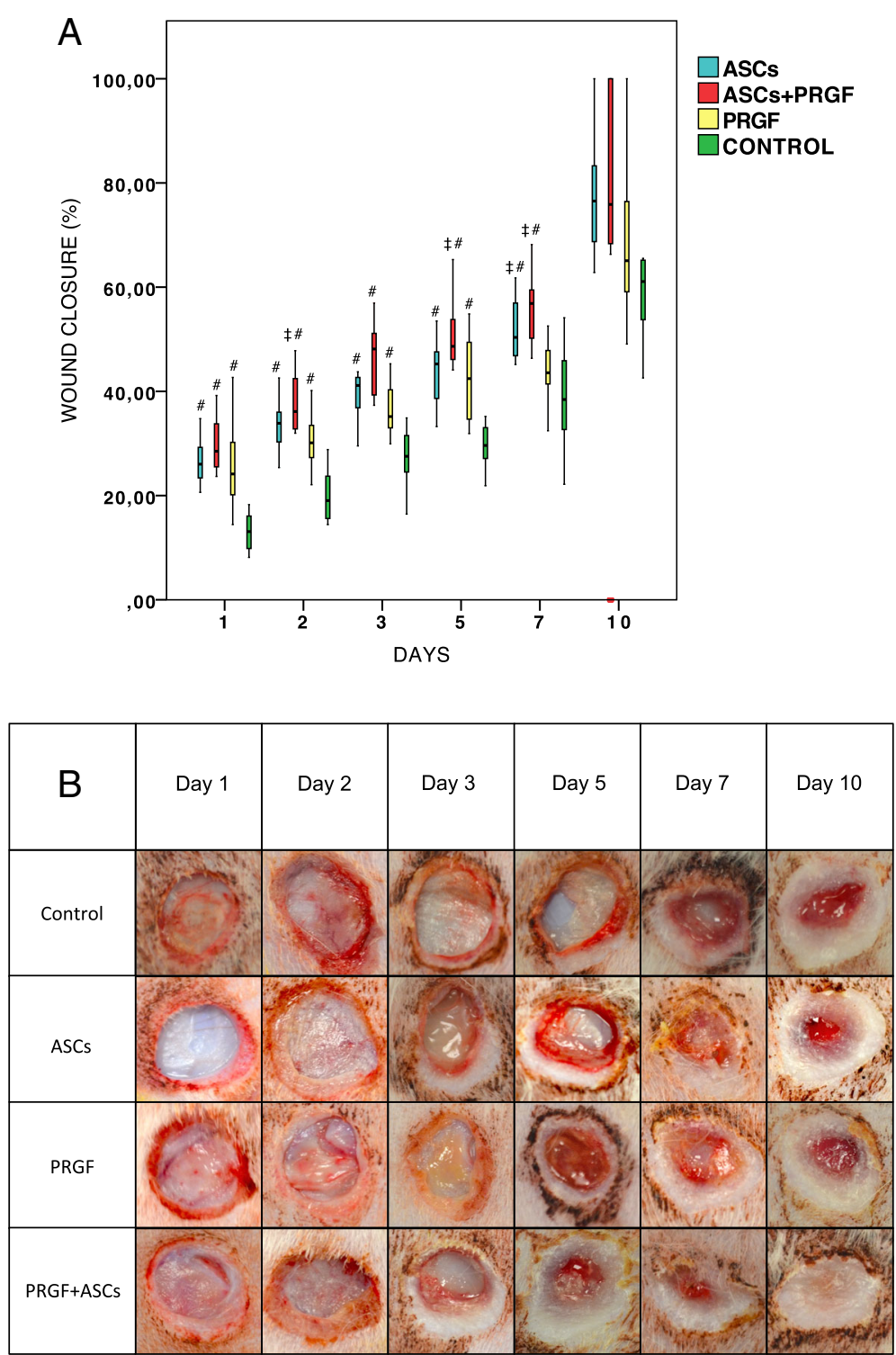

Fig. 2 Macroscopic wound healing evaluation. a Wound closure rates: Comparison in between treatment groups regarding wound closure percentage in each of the studied times. Statistical significant differences between groups are shown with the following: + (ASCs group), + (ASCs +PRGF group), \# (PRGF group), \# (CONTROL group). b Representative photographs of cutaneous wounds from each treatment group at the different studied times

normal in PRGF, ASCs and ASCs+PRGF treated wounds compared with control except for significant better results at days 2 and 3 in scar color and thickness in ASCs and ASCs+PRGF treated wounds $(p<0.05)$.

\section{Histological inflammatory cell infiltration and distribution evaluation}

The observed acute inflammatory infiltrate was mainly composed of neutrophils with an irregular fibrous connective tissue during the first two days. In addition, some macrophages and congestive blood vessels were also evident within the dermis 2-3 days after injury.
A significant decreased inflammatory cell infiltration in all study groups compared with control was observed at days $1,2,3$ and $7(p<0.05)$; in addition, a larger number of animals showed a mild or absent inflammatory infiltrate in ASCs+PRGF group compared with the other treatments throughout the study (Fig. 4). No statistical significant differences were shown regarding inflammatory cell infiltrate distribution throughout the study $(p>0.05)$.

\section{Wound healing angiogenesis assessment}

Masson trichrome staining revealed a significant increase in blood vessel formation in ASCs, PRGF and 


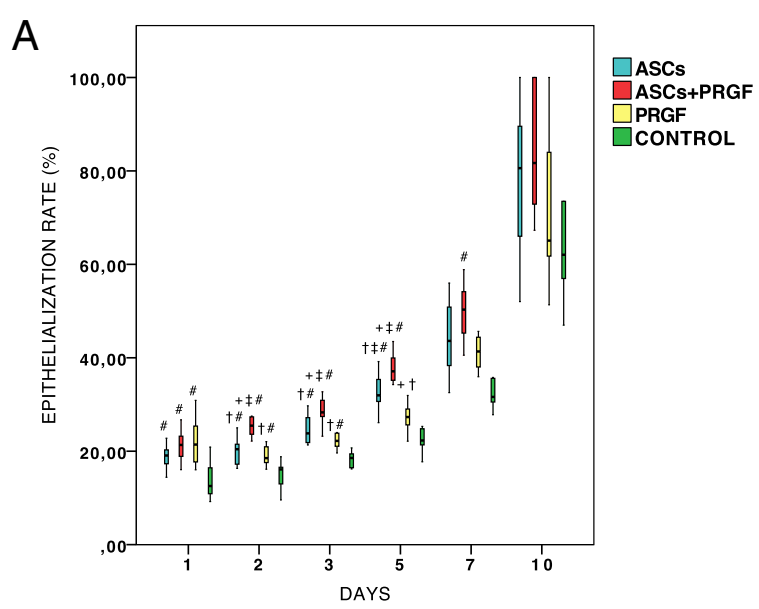

B

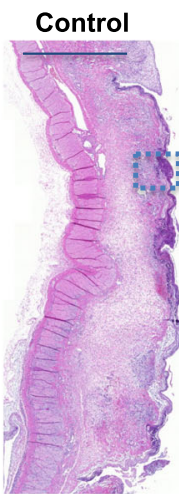

PRGF

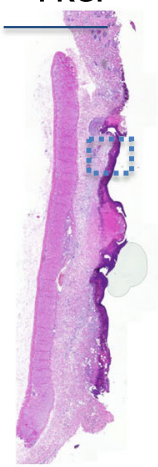

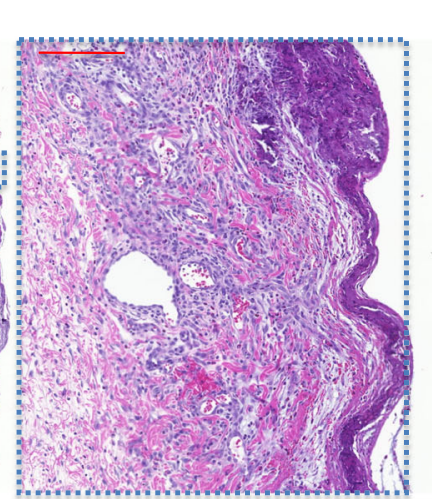

ASCs + PRGF

ASCs
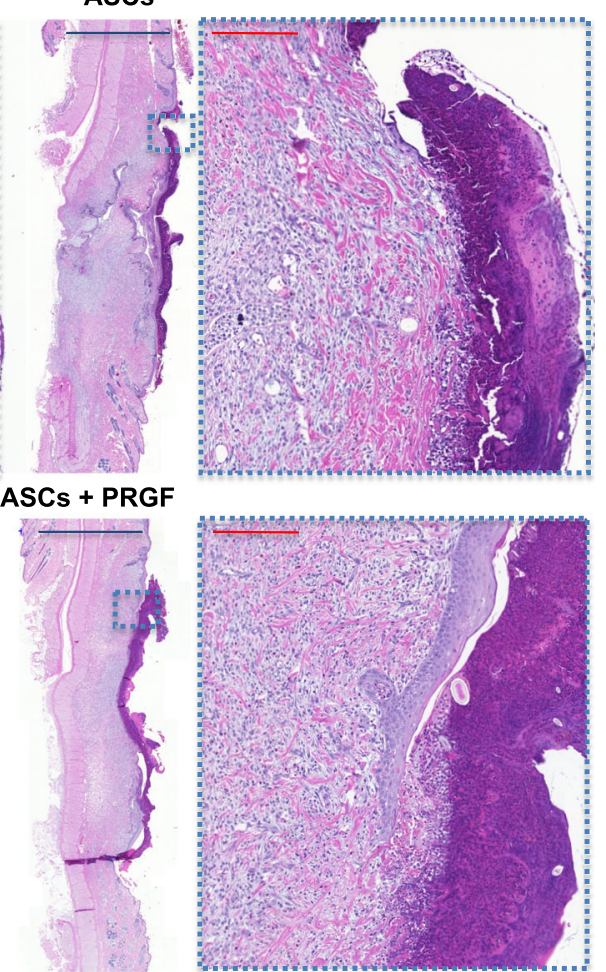

Fig. 3 Microscopic wound healing epithelialization rate evaluation. a Epithelialization rate: Comparison in between treatment groups regarding epithelialization rate percentage in each of the studied times. Statistical significant differences between groups are shown with the following: + (ASCs group), † (ASCs+PRGF group), ‡ (PRGF group), \# (CONTROL group). b Hematoxylin eosin staining. Results from a representative animal within the different treatment groups. Histological images show representative evaluated samples (Blue scale $=2 \mathrm{~mm}$; Red scale $=0,2 \mathrm{~mm}$ )

ASCs+PRGF treated wounds at all studied days compared to control groups $(p=0.010, p=0.001, p=0.001)$. ASCs+PRGF treated wounds produced $2-3$ fold more blood vessels than placebo, PRGF and ASCs groups, with a maximal increase on day 7 (Fig. 5). These results suggest that ASCs+PRGF stimulates angiogenesis in an early phase of the wound healing process; Thus, PGRF +ASCs treatment showed a synergistic response in terms of angiogenesis.
The ASCs treated wounds showed a significant greater blood vessel density compared to control groups at all studied times except for day 3. Additionally, with respect to PRGF group they also demonstrated higher wound vascularity on days 7 and 10 . Moreover, a significant increase in the number of blood vessels was noticeable in the PRGF treated wounds compared to control groups at days 1 and 7 after wounding. 

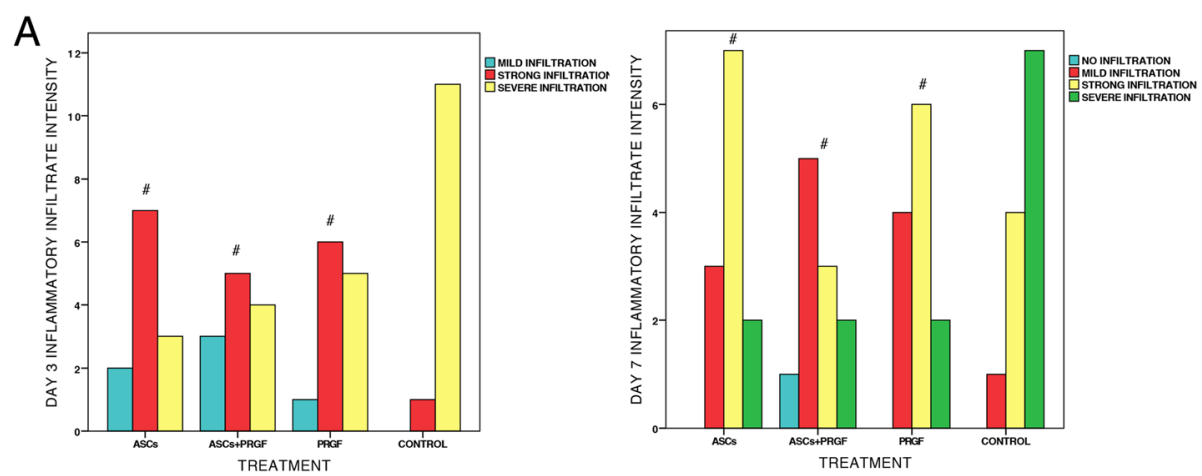

B
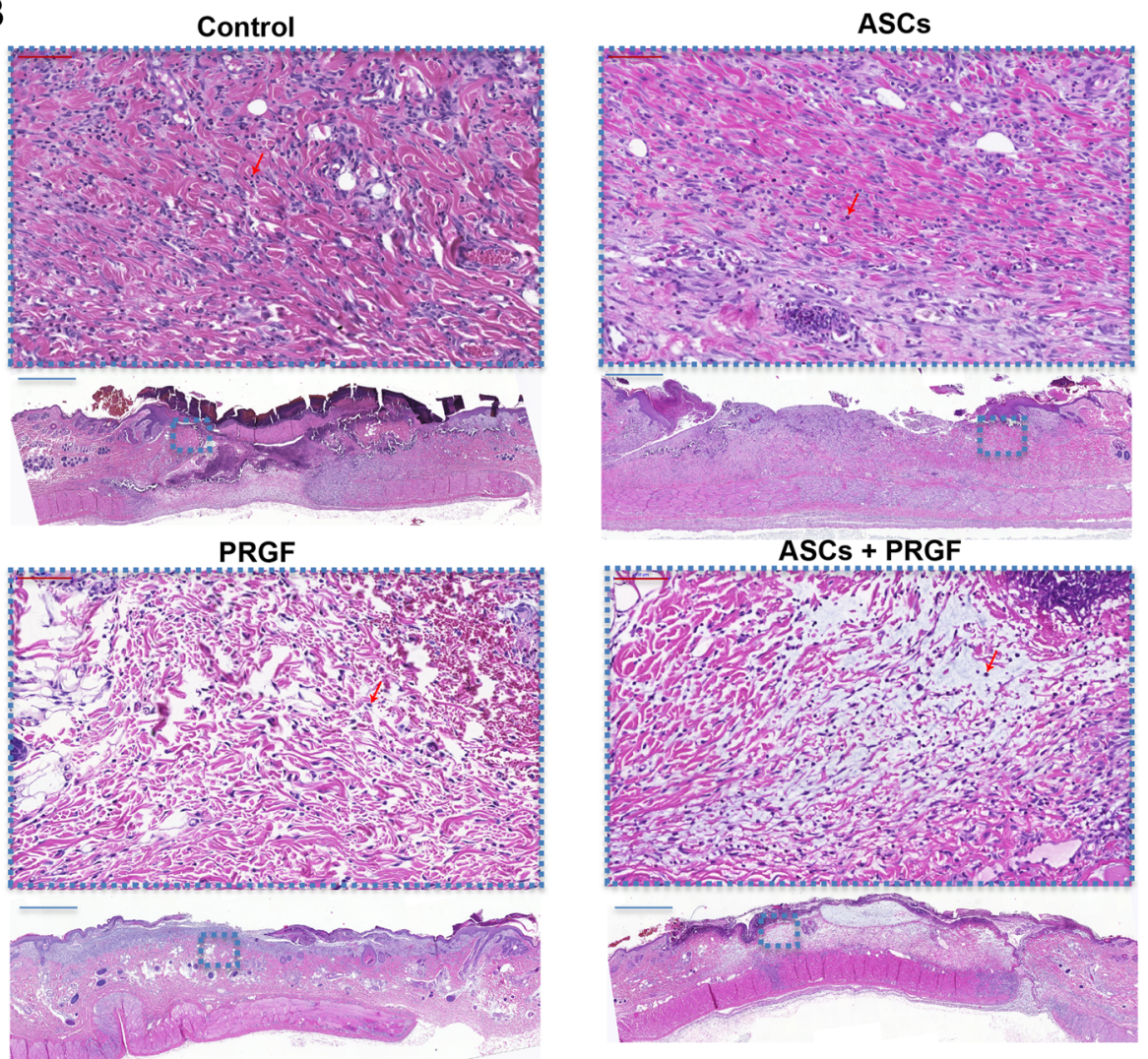

Fig. 4 Microscopic wound healing inflammatory cell infiltration evaluation. a Evaluation of inflammatory cell infiltration intensity: Comparison in between treatment groups regarding inflammatory cell infiltration intensity at representative studies times (Day 3 and 7). Statistical significant differences between groups are shown with the following: + (ASCs group), + (ASCs+PRGF group), ‡ (PRGF group), \# (CONTROL group). b Hematoxylin eosin staining. Results from a representative animal within the different treatment groups. Histological images show representative evaluated samples (Blue scale $=1 \mathrm{~mm}$; Red scale $=0,2 \mathrm{~mm}$ )

\section{Collagen deposition assessment}

Statistical significant differences were obtained in between treatment groups along five checking days except for day 3, appreciating an increase of collagen deposition in ASCs, PRGF and ASCs+PRGF treated wounds with respect to control wounds $(p=0.000)$. Among the treated groups, the highest significant percentage of collagen fibres was shown again by the ASCs+PRGF group not only compared to control groups, but also regarding ASCs treated wounds at day 2 and with PRGF group on days 1, 5, 7 and 10 (Fig. 6).

In the present study, ASCs treated wounds showed significant increased collagen deposition percentages compared to control groups at days 1, 5, 7 and 10.

PRGF infiltrations were found to enhance collagen deposition in our study at days 1, 2 and 5 compared to control groups. 

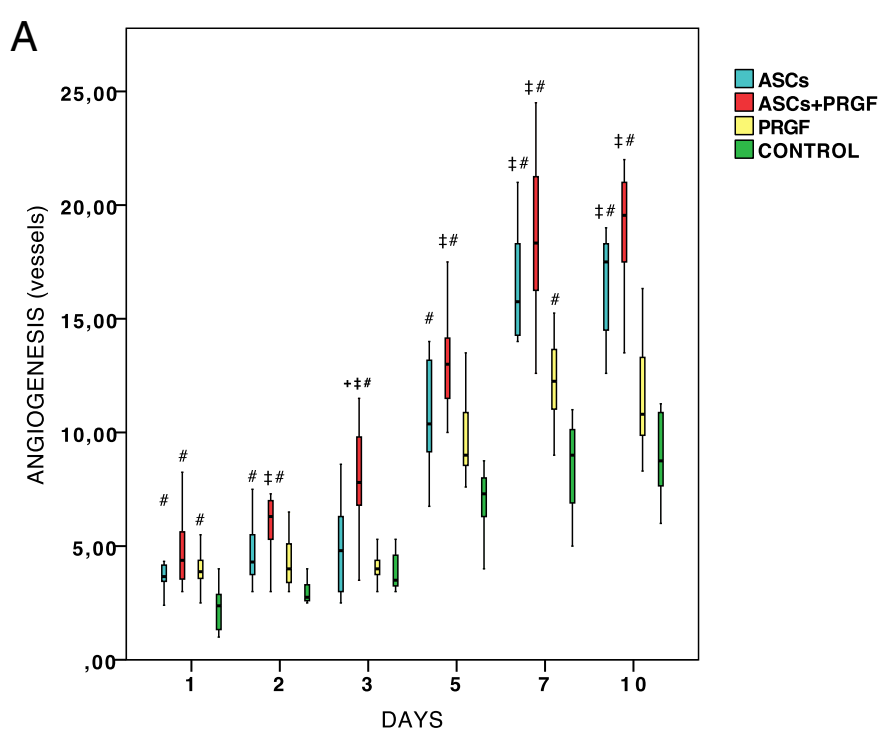

$\mathrm{B}$
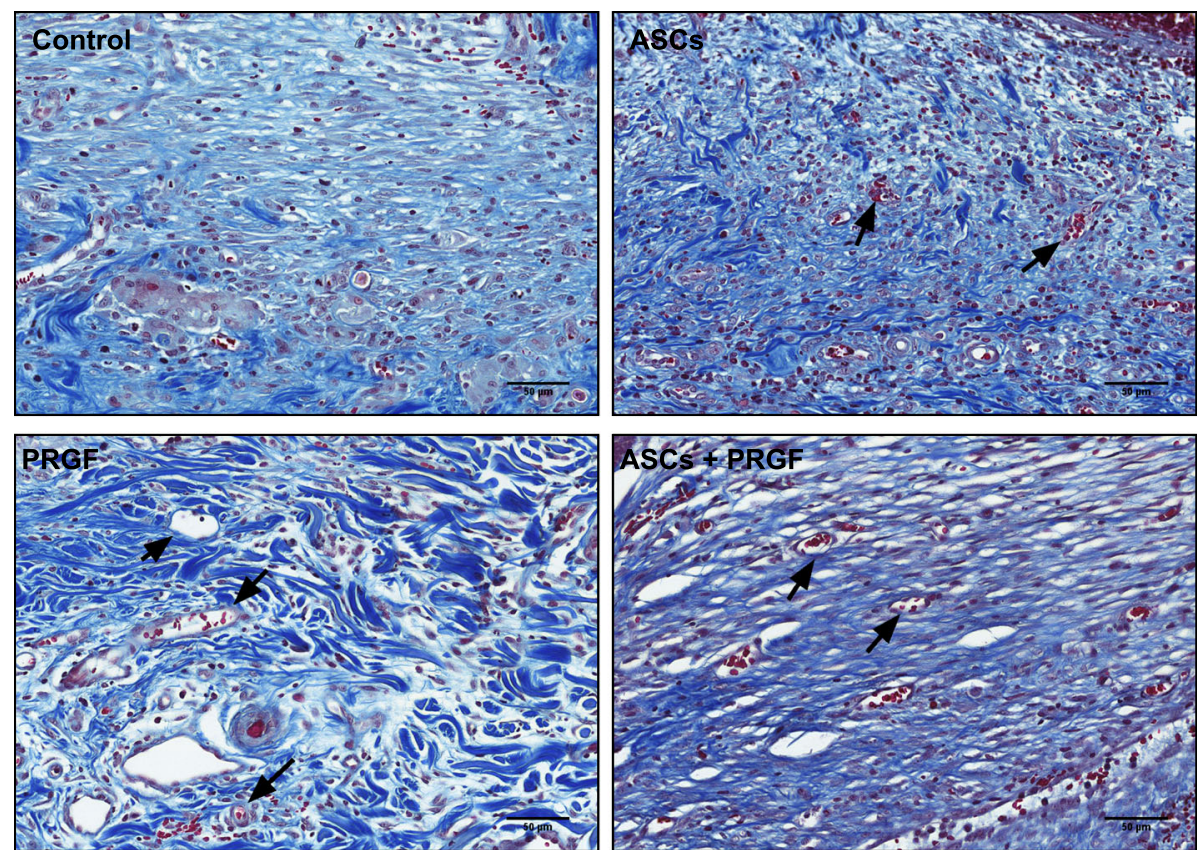

Fig. 5 Microscopic wound healing angiogenesis assessment. a Quantification of new blood vessels: Comparison in between treatment groups regarding angiogenesis in each of the studied times. Statistical significant differences between groups are shown with the following: + (ASCS group), † (ASCs+PRGF group), ₹ (PRGF group), \# (CONTROL group). b Masson trichrome staining. Results from a representative animal within the different treatment groups. Arrows show representative new blood vessels formed (Scale bar $=10 \mathrm{~mm}$ )

\section{Discussion}

\section{Wound closure and epithelialization rate evaluation}

It has been previously proven that PRGF stimulates cell proliferation, chemotaxis and matrix production [26], and there are several studies that show faster wound healing rates as shown in our study when treated with PRGF [26-28].

A positive correlation was shown between macroscopical and histological results that are in agreement with other published data $[13,26,28]$ where both ASCs and PRGF show to enhance reepithelialization and to accelerate wound closure. Furthermore, our results prove that ASCs+PRGF treated wounds offered the best results regarding wound closure and epithelialization. These results are in good agreement with other authors [29] where bone marrow-derived mesenchymal stem cell (BMSCs) plus Plasma rich in Platelets (PRP) treated wounds showed the highest wound healing rate. In this 

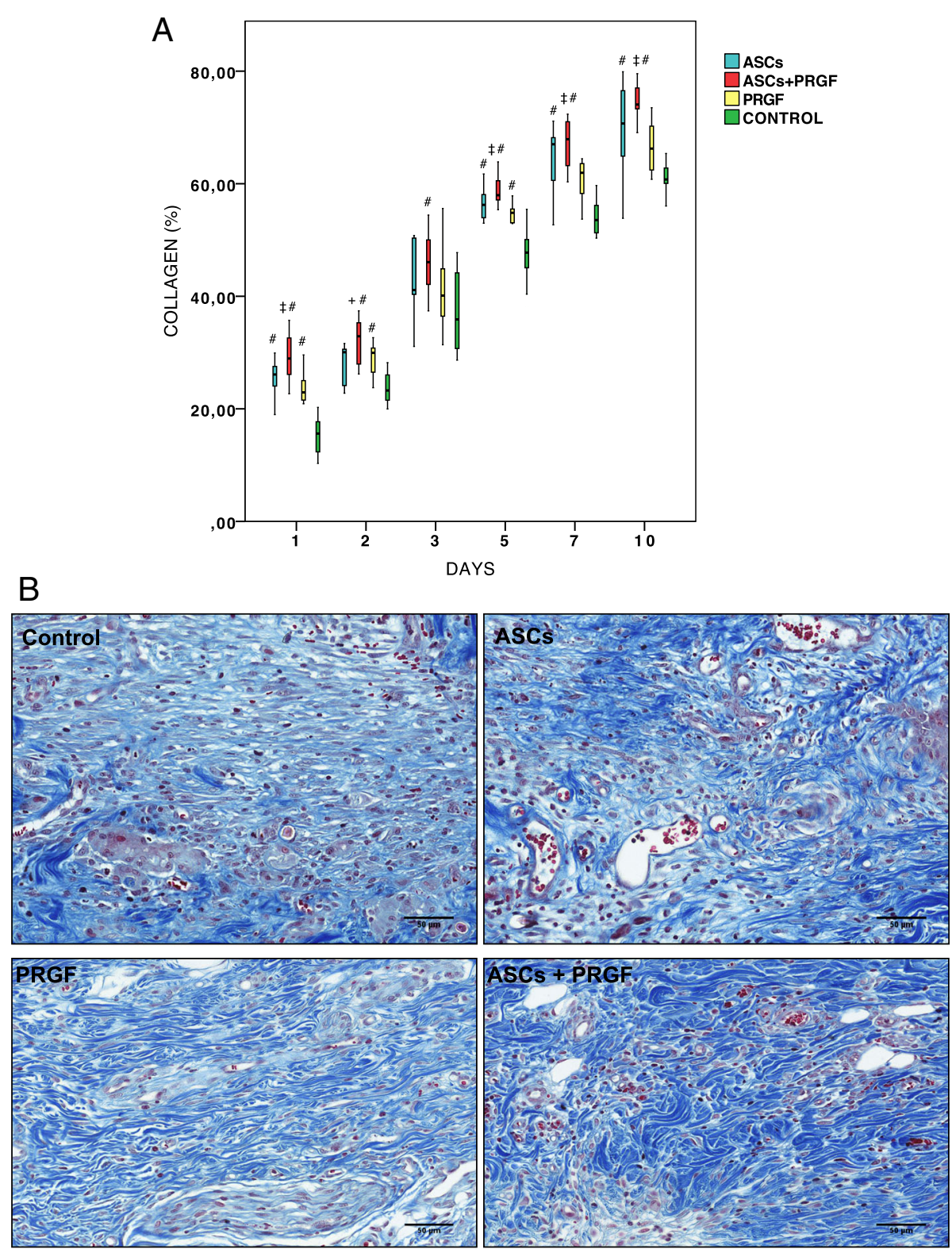

Fig. 6 Microscopic wound healing collagen deposition assessment. a Quantification of collagen deposition percentage: Comparison in between treatment groups regarding collagen deposition percentage in each of the studied times. Statistical significant differences between groups are shown with the following: + (ASCs group), † (ASCs+PRGF group), ₹ (PRGF group), \# (CONTROL group). b Masson trichrome staining. Results from a representative animal within the different treatment groups (Scale bar $=10 \mathrm{~mm}$ )

sense, it is known that PRP preserves the viability of MSCs, stimulates their proliferation and phagocytic activity [9].

\section{Aesthetic assessment of wounds}

Paracrine effects of the ASCs seems to be involved in skin rejuvenation [30] providing antiscarring properties [31]. In agreement with our results, no wound retraction after BMSCs injection to full-thickness wounds was observed in mice [32], while other authors [33] observed a positive color improvement in a canine large skin defect treated with allogenic PRP as shown in our study.

Among the growth factors, it has been reported that TGF- 33 reduces the deposition of collagen during proliferative and remodelling phases, minimizing scar formation [34]. In contrast to the above findings, other studies did not observe significant differences in coloring when PRP was applied probably due to different PRP preparation protocols [35], while in our study significant differences regarding color where observed when PRGF was applied alone or in combination with ASCs compared to control groups $(p<0.05)$. 


\section{Histological inflammatory cell infiltration and distribution evaluation}

In our study, despite the anti-inflammatory properties of PRGF and ASCs when applied alone or combined, a more severe inflammatory cell infiltrate was observed at the beginning of the study compared to the last studied days, this could be due, as suggested by other authors, to an earlier activation of the inflammatory phase, limited during a later phase by PRGF and ASCs [29]. In this sense, MSCs coordinate the effects of inflammatory cells and decrease the secretion of proinflammatory cytokines [2].

Previous studies, in agreement with us, have demonstrated that MSCs exert a suppressive effect on local inflammation. A downregulated expression of pro-inflammatory cytokines was exerted by MSCs when applied topically on canine wounds [36]. Interestingly, a reduced inflammatory infiltration in ASCs treated wounds compared to BMSCs and control wounds was observed in a rabbit cutaneous model [37]. Regarding PRP, studies have shown that PRP may inhibit excessive inflammation and interact with macrophages to improve tissue healing [38]. In accordance with our results, some authors [13] observed a complete resolution of the inflammatory process in PRGF treated wounds at day7, while others [39] at day 28.

In line with our results, other authors have proven a synergistic anti-inflammatory effect in BMSCs+PRP group [29].

\section{Wound healing angiogenesis assessment}

Several studies in agreement with our results have shown that the administration of MSCs to acute and chronic wounds improve wound closure by increasing angiogenesis. This process is attributed to a MSCs paracrine signaling as primary mechanism [2]. In line with our results, in a full thickness excisional injury model in rats, ASCs were shown to enhance neovasculogenesis via secretion of VEGF-A, HGF and FGF-2, and validated the differentiation potential of ASCs into endothelial cells [40]. Moreover, a significant increase in angiogenesis was observed in radiation induced ulcers in rats treated with ASCs [41].

Several growth factors are implicated in neovascularisation, including VEGF, bFGF, PDGF and TGF-B [42]. In concordance with this, enhanced neovascularization was observed, in agreement with our results, by other authors [28] after topical PRP gel application to cutaneous wounds. A significant increased tissue perfusion in PRP-treated flaps and a larger amount of vessels at day 4 was observed in subdermal plexus skin flap in dogs [43]. Moreover, other authors [26, 27] clearly demonstrated that PRGF stimulates angiogenesis.

The combination of ASCs+PRGF showed a synergistic response in terms of angiogenesis in an early phase of the wound healing process, which completely agrees with other author's findings [44].

\section{Collagen deposition assessment}

The highest percentages of collagen deposition were obtained by ASCs+PRGF treated wounds. These results are in good agreement with other authors [29] which showed that PRP + BMSCs group exhibited a higher density of collagen fibres. Once more in correlation with our results, some authors [45] also obtained higher mean percentage values of collagen in MSCs and MSCs + PRP groups in diabetic mice.

In accordance with our results, MSCs coated sutures showed to enhance collagen deposition in sutured tissues [46]. Suggesting that this could be indirectly mediated by MSCs through the release of soluble factors which stimulate collagen synthesis, or directly through the release of collagen by MSCs. Additionally, higher blue staining density in ASCs treated wounds was observed in rabbit full thickness wounds, revealing new collagen deposition [37].

Regarding the use of PRP in cutaneous wounds and in agreement with our results, an increased mean percentage of collagen fibres in PRP treated wounds was observed in rabbits [28].

\section{Conclusion}

In conclusion, our data suggest that perilesional injection of PRGF, ASCs and PRGF+ASCs have the potential to provide a safe and efficient treatment managing to enhance and shorten wound healing process by accelerating wound closure, epithelialization rate, decreasing inflammatory response, increasing angiogenesis and collagen deposition in acute full-thickness cutaneous wounds mainly during the early wound healing period. In addition, better aesthetic results have also been obtained.

However, among the three treatment choices, the most effective was the ASCs+PRGF group, proving a synergistic effect between PRGF and ASCs.

\section{Abbreviations}

ASCs: Adipose-Derived Mesenchymal Stem Cells; BMSCs: Bone Marrow Mesenchymal Stem Cells; EGF: Epidermal Growth Factor; FGF: Fibroblast Growth Factor; IGF: Insulin-like Growth Factor; KGF: Keratinocytes Growth Factor; MMP-2: Matrix Metalloproteinase; MSCs: Mesenchymal Stem Cells; PDGF: Platelet-Derived Growth Factor; PRGF: Plasma Rich in Growth Factors; PRP: Plasma Rich in Platelets; TGF: Transforming Growth Factor; VEGF: Vascular Endothelial Growth Factor

\section{Acknowledgments}

The authors would like to thank the excellent technical support of the technicians at the Molecular Pathology and Translational Research in Oncology in the Research Center of Príncipe Felipe for tissue processing, sectioning and staining. Thanks also to the Cátedra García Cugat for its technical support.

\section{Funding}

This research was financed by García Cugat Foundation for biomedical research and by MINECO (MAT2015-66666-C3-1-R). 


\section{Availability of data and materials}

All data supporting our findings are included in the manuscript. If readers need additional information and/or data sets, they will be provided by the corresponding author upon reasonable request.

\section{Authors' contributions}

DCA performed the experiment, analyzed data and wrote the manuscript. JMC, MRZ and JSJ designed the study and performed the experiment. MRZ performed statistical analysis. JMV proofread the manuscript and gave final approval of the version. RCB supervised all procedures and coordinated the research. BCS participated in performing the experiment. SGL helped with microscopical study. VMM and JFV were responsable for tissue processing, sectioning, staining and in ASCs preparation. All authors read and approved the final manuscript.

\section{Ethics approval}

The research protocol was revised and approved by the Ethical Committee of Animal Welfare (CEBA) of the University CEU Cardenal Herrera of Valencia (Spain) in accordance with Spanish and European legislation.

\section{Consent for publication}

Not applicable.

\section{Competing interests}

The authors declare that they have no competing interests.

\section{Publisher's Note}

Springer Nature remains neutral with regard to jurisdictional claims in published maps and institutional affiliations.

\begin{abstract}
Author details
${ }^{1}$ Bioregenerative Medicine and Applied Surgery Research Group, Animal Medicine and Surgery Department, Veterinary Faculty, Universidad Cardenal Herrera-CEU, CEU Universities, Valencia, Spain. ${ }^{2}$ Orthopaedic service in Hospital Quirón, Artroscopia GC, Barcelona, Spain. ${ }^{3}$ Anatomy and Comparative Pathology Department, Universidad de Córdoba, Córdoba, Spain. ${ }^{4}$ Molecular Pathology and Translational Research in Oncology, Centro de Investigación Príncipe Felipe, Valencia, Spain. ${ }^{5}$ Neuronal and Tissue Regeneration Laboratory, Centro de Investigación Príncipe Felipe, Valencia, Spain. ${ }^{6}$ Animal Pathology Department, IUIBS, Universidad de Las Palmas de
\end{abstract} Gran Canaria, 35416, Transmontaña s/n, Arucas, Las Palmas, Spain.

\section{Received: 19 January 2018 Accepted: 16 August 2018}

\section{Published online: 21 September 2018}

\section{References}

1. Singer AJ, Clark RA. Cutaneous wound healing. N Engl J Med. 1999;341(10): 738-46.

2. Maxson S, Lopez EA, Yoo D, Danilkovitch-Miagkova A, Leroux MA. Concise review: role of mesenchymal stem cells in wound repair. Stem Cells Transl Med. 2012;1(2):142-9.

3. Ko SH, Nauta A, Wong V, Glotzbach J, Gurtner GC, Longaker MT. The role of stem cells in cutaneous wound healing: what do we really know? Plast Reconstr Surg. 2011;127(Suppl 1):10S-20S.

4. Braiman-Wiksman L, Solomonik I, Spira R, Tennenbaum T. Novel insights into wound healing sequence of events. Toxicol Pathol. 2007;35(6):767-79.

5. Weinstein-Oppenheimer CR, Aceituno AR, Brown DI, Acevedo C, Ceriani R, Fuentes MA, et al. The effect of an autologous cellular gel-matrix integrated implant system on wound healing. J Transl Med. 2010;8:59.

6. Borena BM, Martens A, Broeckx SY, Meyer E, Chiers K, Duchateau L, et al. Regenerative skin wound healing in mammals: state-of-the-art on growth factor and stem cell based treatments. Cellular physiology and biochemistry. Cell Physiol Biochem. 2015;36(1):1-23.

7. Dieckmann C, Renner R, Milkova L, Simon JC. Regenerative medicine in dermatology: biomaterials, tissue engineering, stem cells, gene transfer and beyond. Exp Dermatol. 2010;19(8):697-706.

8. Isakson M, de Blacam C, Whelan D, McArdle A, Clover AJ. Mesenchymal stem cells and cutaneous wound healing: current evidence and future potential. Stem Cells Int. 2015;2015:831095.

9. Griffeth RJ, Garcia-Parraga D, Mellado-Lopez M, Crespo-Picazo JL, SorianoNavarro M, Martinez-Romero A, et al. Platelet-rich plasma and adipose- derived mesenchymal stem cells for regenerative medicine-associated treatments in bottlenose dolphins (Tursiops truncatus). PLoS One. 2014;9(9): e108439.

10. Cervelli V, Gentile P, Scioli MG, Grimaldi M, Casciani CU, Spagnoli LG, et al. Application of platelet-rich plasma in plastic surgery: clinical and in vitro evaluation. Tissue Eng Part C Methods. 2009;15(4):625-34

11. Kim WS, Park BS, Sung JH, Yang JM, Park SB, Kwak SJ, et al. Wound healing effect of adipose-derived stem cells: a critical role of secretory factors on human dermal fibroblasts. J Dermatol Sci. 2007:48(1):15-24.

12. Hassan WU, Greiser U, Wang W. Role of adipose-derived stem cells in wound healing. Wound Repair Regen. 2014;22(3):313-25.

13. Molina-Minano F, Lopez-Jornet P, Camacho-Alonso F, Vicente-Ortega V. The use of plasma rich in growth factors on wound healing in the skin: experimental study in rabbits. Int Wound J. 2009;6(2):145-8.

14. Li J, Chen J, Kirsner R. Pathophysiology of acute wound healing. Clin Dermatol. 2007;25(1):9-18.

15. Suthar M, Gupta S, Bukhari S, Ponemone V. Treatment of chronic nonhealing ulcers using autologous platelet rich plasma: a case series. J Biomed Sci. 2017;24(1):16.

16. Anitua E, Sanchez M, Orive G, Andia I. The potential impact of the preparation rich in growth factors (PRGF) in different medical fields. Biomaterials. 2007;28(31):4551-60.

17. de Vos RJ, van Veldhoven PL, Moen MH, Weir A, Tol JL, Maffulli N. Autologous growth factor injections in chronic tendinopathy: a systematic review. Br Med Bull. 2010;95:63-77.

18. Sommeling CE, Heyneman A, Hoeksema H, Verbelen J, Stillaert FB, Monstrey S. The use of platelet-rich plasma in plastic surgery: a systematic review. J Plast Reconstr Aesthet Surg. 2013:66(3):301-11.

19. Teymur H, Tiftikcioglu YO, Cavusoglu T, Tiftikcioglu Bl, Erbas O, Yigitturk G, et al. Effect of platelet-rich plasma on reconstruction with nerve autografts. Med Sci. 2017;33(2):69-77.

20. Schneppendahl J, Jungbluth $P$, Logters $\Pi$, Sager M, Wild M, Hakimi M, et al. Treatment of a diaphyseal long-bone defect with autologous bone grafts and platelet-rich plasma in a rabbit model. Vet Comp Orthop Traumatol. 2015;28(3):164-71.

21. Moneib HA, Youssef SS, Aly DG, Rizk MA, Abdelhakeem YI. Autologous platelet-rich plasma versus conventional therapy for the treatment of chronic venous leg ulcers: a comparative study. J Cosmet Dermatol. 2017; https://doi.org/10.1111/jocd. 12401

22. Vilar JM, Morales M, Santana A, Spinella G, Rubio M, Cuervo B, et al. Controlled, blinded force platform analysis of the effect of intraarticular injection of autologous adipose-derived mesenchymal stem cells associated to PRGF-Endoret in osteoarthritic dogs. BMC Vet Res. 2013:9:131.

23. Rodriguez-Jimenez FJ, Valdes-Sanchez T, Carrillo JM, Rubio M, MonleonPrades M, Garcia-Cruz DM, et al. Platelet-rich plasma favors proliferation of canine adipose-derived mesenchymal stem cells in methacrylate-endcapped caprolactone porous scaffold niches. J Funct Biomater. 2012;3(3):556-68.

24. Maharlooei MK, Bagheri M, Solhjou Z, Jahromi BM, Akrami M, Rohani L, et al Adipose tissue derived mesenchymal stem cell (AD-MSC) promotes skin wound healing in diabetic rats. Diab Res Clin Prac. 2011;93(2):228-34.

25. Lowry BP, Bradfield JF, Carroll RG, Brewer K, Meggs WJ. A controlled trial of topical nitroglycerin in a New Zealand white rabbit model of brown recluse spider envenomation. Ann Emerg Med. 2001;37(2):161-5.

26. Sell SA, Wolfe PS, Spence AJ, Rodriguez IA, McCool JM, Petrella RL, et al. A preliminary study on the potential of manuka honey and platelet-rich plasma in wound healing. Int J Biomater. 2012;2012:313781.

27. Park YG, Lee IH, Park ES, Kim JY. Hydrogel and platelet-rich plasma combined treatment to accelerate wound healing in a nude mouse model. Arch Plast Surg. 2017:44(3):194-201.

28. Ostvar O, Shadvar S, Yahaghi E, Azma K, Fayyaz AF, Ahmadi K, et al. Effect of platelet-rich plasma on the healing of cutaneous defects exposed to acute to chronic wounds: a clinico-histopathologic study in rabbits. Diagn Pathol. 2015;10:85.

29. Lian Z, Yin X, Li H, Jia L, He X, Yan Y, et al. Synergistic effect of bone marrow-derived mesenchymal stem cells and platelet-rich plasma in streptozotocin-induced diabetic rats. Ann Dermatol. 2014;26(1):1-10.

30. Hanson SE, Gutowski KA, Hematti P. Clinical applications of mesenchymal stem cells in soft tissue augmentation. Aesthet Surg J. 2010;30(6):838-42.

31. Colwell AS, Beanes SR, Soo C, Dang C, Ting K, Longaker MT, et al. Increased angiogenesis and expression of vascular endothelial growth factor during scarless repair. Plast Reconstr Surg. 2005;115(1):204-12. 
32. Mansilla E, Marin GH, Sturla F, Drago HE, Gil MA, Salas E, et al. Human mesenchymal stem cells are tolerized by mice and improve skin and spinal cord injuries. Transplant Proc. 2005;37(1):292-4.

33. Chung TH, Baek DS, Kim N, Park JH, Park C. Topical allogeneic platelet-rich plasma treatment for a massive cutaneous lesion induced by disseminated intravascular coagulation in a toy breed dog. Ir Vet J. 2015;68(1):4.

34. Enoch S, Grey JE, Harding KG. Recent advances and emerging treatments. BMJ. 2006;332(7547):962-5.

35. Abegao KG, Bracale BN, Delfim IG, Santos ES, Laposy CB, Nai GA, et al. Effects of heterologous platelet-rich plasma gel on standardized dermal wound healing in rabbits. Acta Cir Bras. 2015;30(3):209-15.

36. Kim JW, Lee JH, Lyoo YS, Jung DI, Park HM. The effects of topical mesenchymal stem cell transplantation in canine experimental cutaneous wounds. Vet Dermat. 2013;24(2):242-e253.

37. Pelizzo G, Avanzini MA, Icaro Cornaglia A, Osti M, Romano P, Avolio L, al e. Mesenchymal stromal cells for cutaneous wound healing in a rabbit model: pre-clinical study applicable in the pediatric surgical setting. J Transl Med. 2015;13:219.

38. Mishra A, Pavelko T. Treatment of chronic elbow tendinosis with buffered platelet-rich plasma. Am J Sports Med. 2006;34(11):1774-8.

39. Lopez-Jornet P, Camacho-Alonso F, Molina-Minano F, Vicente-Ortega V. Effects of plasma rich in growth factors on wound healing of the tongue. Experimental study on rabbits Medicina oral, patologia oral y cirugia bucal. 2009;14(9):e425-8.

40. Nie C, Yang D, Xu J, Si Z, Jin X, Zhang J. Locally administered adiposederived stem cells accelerate wound healing through differentiation and vasculogenesis. Cell Transplant. 2011;20(2):205-16.

41. Huang SP, Huang CH, Shyu JF, Lee HS, Chen SG, Chan JY, et al. Promotion of wound healing using adipose-derived stem cells in radiation ulcer of a rat model. J Biomed Sci. 2013;20:51.

42. Park HJ, Lee $\mathrm{S}$, Kang $\mathrm{KH}, \mathrm{Heo} \mathrm{CY}$, Kim JH, Yang HS, et al. Enhanced random skin flap survival by sustained delivery of fibroblast growth factor 2 in rats. ANZ J Surg. 2013;83(5):354-8.

43. Karayannopoulou M, Papazoglou LG, Loukopoulos P, Kazakos G, Chantes A, Giannakas N, et al. Locally injected autologous platelet-rich plasma enhanced tissue perfusion and improved survival of long subdermal plexus skin flaps in dogs. Vet Comp Orthop and Traumatol. 2014:27(5):379-86.

44. Heo SC, Jeon ES, Lee IH, Kim HS, Kim MB, Kim JH. Tumor necrosis factoralpha-activated human adipose tissue-derived mesenchymal stem cells accelerate cutaneous wound healing through paracrine mechanisms. J Invest Dermatol. 2011;131(7):1559-67.

45. Argolo Neto NM, Del Carlo RJ, Monteiro BS, Nardi NB, Chagastelles PC, de Brito AF, et al. Role of autologous mesenchymal stem cells associated with platelet-rich plasma on healing of cutaneous wounds in diabetic mice. Clin Exp Dermatol. 2012;37(5):544-53.

46. Casado JG, Blazquez R, Jorge I, Alvarez V, Gomez-Mauricio G, Ortega-Munoz $M$, et al. Mesenchymal stem cell-coated sutures enhance collagen depositions in sutured tissues. Wound Repair Regen. 2014;22(2):256-64.

Ready to submit your research? Choose BMC and benefit from:

- fast, convenient online submission

- thorough peer review by experienced researchers in your field

- rapid publication on acceptance

- support for research data, including large and complex data types

- gold Open Access which fosters wider collaboration and increased citations

- maximum visibility for your research: over $100 \mathrm{M}$ website views per year

At $\mathrm{BMC}$, research is always in progress.

Learn more biomedcentral.com/submissions 